\title{
Should a Minimum Income be Unconditional?
}

Stuart White, Jesus College, Oxford. September 2016.

Forthcoming in Stafano Civitarese and Simon Halliday, eds., The Fate of Social Welfare in an Age of Austerity: Socio-Economic Rights in Europe, London: Routledge.

\section{Introduction}

It is widely accepted that in a just society citizens must have access to an income sufficient to meet basic needs, a minimum income. However, in most welfare states, for most citizens of working age, access to a minimum income is typically conditional on employment-related activity such as job search, training or work itself. Moreover, as a number of contributions to this volume show, the policy trend for many years - preceding the financial crash - has been in the direction of increased work conditionality in this sense. ${ }^{1}$ Is work conditionality justifiable? Should access to a minimum income be unconditional, at least in this work-related respect? In this paper I shall explore a case for unconditional minimum income (UMI). The core idea is that while conditionality is justified under appropriate circumstances, there is always a significant risk that the relevant conditions will not hold, rendering conditionality unjust. Moreover, the dangers from unjust conditionality can be severe. How should we respond to this context of risk and danger? I argue for a pluralistic response within which one element is to work to diminish conditionality and to shift towards a UMI.

I begin in section 1 with a discussion of possible justifications for conditionality. Having first shown that the issue is not settled simply by invoking the concept of 'social rights', I note how paternalist and fairness arguments are offered for conditionality. I elaborate the fairness argument for conditionality which focuses on the principle of reciprocity: that those who choose to share in the benefits created by others' productive efforts should make a reciprocal effort in return. I indicate how this principle, far from being 
a 'neo-liberal' idea, is deeply rooted in egalitarian traditions of political thought and how making a minimum income conditional on work is also a common-place within this tradition.

Section 2 then situates the reciprocity principle within a wider discussion of economic fairness. The obligations we have under this principle, which putatively justify conditionality, must be understood in the context of various rights we have to fair treatment in the organisation of our economic system. Under justice as fair reciprocity, the obligation to work, as an expression of the reciprocity principle, is conditional on these rights being sufficiently met. When they are not, conditionality is unjust: it enforces an obligation that does not obtain and, in the process, might also threaten to deepen the unjust disadvantage suffered by some. In this important sense, therefore, the justice of conditionality is conditional.

What if, as is arguably the case in many Euro-Atlantic nations today, the conditions for just conditionality are not met? Section 3 discusses three responses. One response, of course, is to redouble our efforts to bring about the economic and social conditions under which conditionality is just. A second response is to think about the political processes through which conditionality is decided and designed and to consider how those subject to conditionality can have greater voice in these processes. A third response is to eschew conditionality in view of the risks and dangers it holds and seek to move towards a UMI. There is something apparently odd in this argument for UMI in that it seems simultaneously to be sceptical of our capacity as democratic citizens (to create the conditions of fair reciprocity) while also optimistic about it (to enact an UMI). However, I argue that this asymmetry is plausible, and so does not undermine this case for UMI. Section 4 concludes.

\section{Why conditionality?}

Getting a minimum income through the welfare state is 'conditional' when eligibility for the cash payments is linked to the satisfactory performance of behavioural requirements, typically related to employment, e.g., job search, training, or 'work' itself. A minimum 
income is unconditional, in the sense I intend here, when eligibility lacks any conditionality of this behavioural kind. If a society ensures all citizens an income on this unconditional basis at a level sufficient to meet basic needs then it gives its citizens an unconditional minimum income or UMI. Note that as defined here, an UMI is not necessarily a universal cash grant. A UMI could take the form of a Negative Income Tax, i.e., could incorporate a means-test. I put that design issue to one side for this paper and focus just on the issue of conditionality related to behaviour, and to employment-related conditionality in particular.

Conditionality of this kind is sometimes said to be necessarily in tension with the idea that a minimum income as the focus of a 'social right' as an element of what T.H. Marshall termed 'social citizenship' (Marshall 1950, White 2000). Rights, so the argument goes, have an intrinsic quality of being unconditional. So if a minimum income is the focus of a social right, it might seem that receipt of a minimum income must itself be unconditional. To advocate conditionality, on this view, is to imply that minimum income is not the focus of a 'social right' and, thus, implies a rejection of the philosophy of 'social citizenship'. However, as I have argued in earlier work, the issue is not so straightforward (White 2000, 2003). When we say that a minimum income is the focus of a social right, we have to be clear as to what exactly this means. Is the right in question a right to be given a minimum income? Or is it a right of reasonable access to a minimum income? The social right to a minimum income can be understood, fundamentally, as a right of the citizen to have reasonable access to a minimum income. For some citizens this might well imply a right to be given a minimum income because they lack the capacity and/or opportunity to acquire an income through their own efforts. But if, say, an individual is able to work, and society offers them a job as a means of earning a minimum income, and this job is not itself in any way degrading or harmful, then this individual arguably has reasonable access to a minimum income even if they are not given this income. The reasonable access consists, precisely, in their access to 
this job. By extension, a welfare state that offers citizens access to a minimum income but subject to forms of conditionality is not necessarily violating their social rights: as in the hypothetical job example, the work-related conditionality of the minimum income may be consistent with the right of reasonable access to a minimum income.

That all said, however, we surely do need a good reason to insist on conditionality. It is not reasonable to make the income conditional on an arbitrary basis. What reason, or reasons, then might we have? Two promising reasons are paternalism and fairness. On the paternalist view, conditionality is justified because it is good for the 'welfare recipient' (Mead 1992). It is of benefit to receivers of income support that they are subject to behavioural requirements, e.g., because, it is alleged, attachment to employment is good for well-being and conditionality helps to maintain this attachment. According to the fairness argument, it is part of a fair scheme of social cooperation that people receive income support conditionally (when it is reasonable to expect them to meet the relevant behavioural requirements); the conditions help promote behaviour that is fair to others. I will focus on the fairness argument here.

There are of course many different theories of distributive justice and so potentially many accounts of how conditionality is linked to fairness. One idea one sometimes hears is that citizens have an obligation to be 'self-sufficient'. Conditionality is then defended as a means of encouraging self-sufficiency. Self-sufficiency here means, primarily, that one enjoys an income without the need to draw on state transfers. Thus, self-sufficiency is logically connected to the idea, prominent in many governments' justifications for reforms to the benefits system, that 'benefit dependency' is a bad in itself (see Roman, Meers, this volume). ${ }^{2}$ One feature of this view, however, is that it seems to assume that the distribution of income generated through the market is presumptively just. 'Transfers' effected through the tax-benefit system then look like intrusions into the underlying, presumptively just market- 
based distribution, and, as intrusions, they look like something that needs to be discouraged. However, from the standpoint of many theories of justice (such as that of John Rawls, for example), we may not regard a market-generated distribution as presumptively just. A just distribution may be one that is produced through a market system that itself operates on the basis of highly 'redistributive' tax-benefit rules. Taxes and transfers are not, on this view, necessarily intrusions into a just distribution. Rather, they help to define what a just distributive scheme really is. On this view, however, there is no reason to think that there is a general duty to achieve 'self-sufficiency' in the original sense. Receiving a high level of transfers through the tax-benefit system might be exactly what justice demands for a given individual, and there is no wrong here that stands in need of correction through extra effort on their part.

The idea of self-sufficiency must be clearly distinguished from another idea which can also feature in fairness arguments for conditionality: the idea of reciprocity. According to what we may term the reciprocity principle, each of us owes our society, as a matter of fairness, a reasonable productive contribution in return for receiving a sufficiently fair share of the economic benefits generated by our fellow citizens. The idea is not the same as selfsufficiency because it does not imply that everyone should ideally have an income entirely independent of state transfers. It does not necessarily imply that people should 'put in' economically goods or services equivalent in value to what they 'take out' (an idea close to, though not quite the same as, self-sufficiency). It may mean, rather, that all citizens, sharing in their society's collective product, 'do their bit', within the bounds of their respective capacities and opportunities, to contribute to this product. Conditionality in the income support system is then presented as a means of ensuring that citizens do not enjoy income support on terms that violate the reciprocity principle (White 2000, 2003, 2004). 
So understood, the reciprocity principle, and the advocacy of conditionality based on this principle, actually has strong roots in traditions of egalitarian political thought. Unlike the idea of self-sufficiency, it is by no means in itself a 'right-wing' or 'neo-liberal' idea. By way of illustration, consider the writings of the Spanish anarchist-communist, Isaac Puente. Puente's Libertarian Communism was adopted as the platform of the anarcho-syndicalist trade union, the CNT, in 1936, just prior to the outbreak of the Spanish Civil War (Puene 1932). Puente says here that 'libertarian communism' will 'bring into common ownership everything that goes to make up the wealth of society...' and at the same time 'make it a common obligation that each contribute to...production according to their energies and talents...' with the resulting output distributed according to need (Puente 1932, 28). Puente clarifies what is involved in making contribution to production a 'common obligation.' In rural areas, he says: 'Whosoever refuses to work for the community (aside from the children, the sick, and the old) will be stripped of their other rights: to deliberate [in the local council] and to consume' (Puente 1932, 43). Meanwhile, in the towns, unions will issue each worker with a 'producer's pass-book.' The pass-book will include details about consumption needs ('for instance, size of family') but 'the number of days and hours worked will also be noted in these pass-books.' The pass-book entitles the worker to goods and services: 'The only persons exempted from this requirement will be children, the aged, and the infirm' (Puente $1932,44)$

Puente is far from being unusual on the socialist left in insisting on work as a condition of income (with exceptions for children, the aged and for sick and disabled people). Gerrard Winstanley, the $17^{\text {th }}$ century English 'Digger'; Karl Marx; Rosa Luxemburg; and R.H. Tawney, all argue that income is properly conditional on work in a non-/post-capitalist society (White 2003, pp.52-59). Underpinning much of this left advocacy of conditionality is commitment to some version of the reciprocity principle. 


\section{2. 'Conditionality is conditional' 3}

The reciprocity principle, however, is just one aspect of the broader idea of organizing economic structures so that they embody fair terms of social cooperation (Rawls 1999, Shelby 2007). This wider notion of fair terms of social cooperation provides crucial context for the reciprocity principle. It both supports it, and points to a range of other considerations that shape and constrain fairness in the application of the reciprocity principle. Let's outline some of these conditions for fair reciprocity.

(1) Reciprocity-based work obligations must be applied consistently and equitably.

A first set of conditions for fair reciprocity concern consistency and equity in enforcing work-related, reciprocity-based obligations. For example, if work obligations are enforced through the income support system, fairness requires that these obligations are enforced equally for all receiving income support payments. Like cases must be treated alike in the administration of the relevant conditionality rules. ${ }^{4}$

Second, if work obligations are enforced through the income support system, fairness requires that they are also enforced for others in a position to get an income without satisfying the reciprocity principle. In capitalist societies some people are able to enjoy income without working because of their ownership of assets. In some cases, this may be connected with productive contributions in ways that make the income consistent with the reciprocity principle. But in some cases, this will not be the case. For example, if someone inherits a large fortune and then lives of the return on the inherited assets, this may well mean they are able to enjoy an income without meeting the reciprocity principle. Large capital gains that accrue to asset-owners without any productive effort on their part also have this 'unearned' quality and enable the owners to get goods and services without satisfying the reciprocity principle. Equity in the enforcement of reciprocity-based work obligations requires that we avoid the asymmetry which consists in targeting those making use of the 
income support system while ignoring these kinds of asset-based income. The fact that many of the asset rich choose to work is not pertinent. The point is that they have the freedom not to that we are denying the asset-poor when we enforce work obligations through the income support system. ${ }^{5}$

Thirdly, if work obligations are enforced through the income support system, fairness requires they are enforced in ways that respect due process and which prevent the imposition of requirements that are unreasonable. Those subject to conditionality must have adequate rights to challenge decisions made about their eligibility and not stand at the mercy of bureaucratic judgment. In addition, the conditions themselves must be reasonable in content. In particular, they must not require activity that is degrading or damaging to the individual.

Thus far, we have spoken about 'work' and 'employment' in more or less interchangeable terms. However, much work in our societies is not done in an employment relationship or, indeed, as self-employment. For example, many citizens, especially women, do unpaid care work for family and friends. A fourth aspect of equity in the application of the reciprocity principle is that as a society we recognise the ways in which this work may also meet citizens' obligations under the reciprocity principle. We should avoid equating reciprocity-satisfying contribution reductively with market-facing work to the exclusion of unpaid care work (Cochrane et al 2010). This is one reason why if carers are subject to conditionality rules, the obligations defined under these rules must be reasonable in light of their responsibilities as carers.

(2) The fairness of enforcing work-related activity in the income support system depends on the wider fairness of the economic system.

Our points above about asset-based incomes and recognising the contribution of unpaid care work begin to show how fairness in the application of the reciprocity principle requires us to look at the wider structure of the economy. This point needs to be expanded. If 
we have reciprocity-based obligations to work, then we have them in the context of an economy and society that treats us sufficiently fairly in other important respects. Intuitively, it is reasonable to expect us to do our bit for a cooperative scheme that has our interests at heart as much as anyone else's. But if the scheme we belong to evidently denies us fair opportunity and reward, then the obligation to do our bit does not apply. Nobody has an obligation to do their bit in a cooperative venture that is designed in a way that unfairly does them down. As suggested, this has implications both for the structure of opportunity, affecting access to things like education, jobs and finance; and for the structure of rewards, including, centrally, the distribution of after-tax income from work. The essential point is made effectively by Tommie Shelby in his discussion of whether work obligations apply to the black ghetto poor in the USA:

'...job opportunities for low-skilled workers are severely limited and the jobs that are available are often menial, dead-end service positions that pay wages too low to provide adequate economic security for a family. Now it might be replied that if the ghetto poor do not want to take these low-wage jobs they should develop their skills....As is widely known, however, the quality of education available to ghetto residents is generally so substandard that most cannot get a basic education there, let alone proper preparation for college.... This lack of equal educational opportunity, which in turn creates an unfair employment opportunity scheme, vitiates any obligation to work...' (Shelby 2007, pp.146-147).

As Shelby explains, this does not mean the ghetto poor (or radically unjustly disadvantaged individuals more generally) have no duties. They retain 'natural duties' to one another and to others, as persons, including the duty to help to create just social structures (Shelby 2007, 144-159). But specifically 'civic obligations', such as the obligation to work, which are a matter of reciprocity to one's fellow citizens in the context of a cooperative scheme between equals, do not apply when the cooperative scheme is radically unfair (to those who are disadvantaged by this radical unfairness). Note also that any effort to enforce these supposed, but actually non-existent work obligations might have the effect of consolidating or exacerbating aspects of the underlying unjust disadvantage. For example, 
conditionality rules might have the effect of weakening the bargaining power of disadvantaged workers thereby consolidating or exacerbating the low rewards they receive. In themselves, the rules may add stress and suffering to the lives of disadvantaged workers, thereby exacerbating their disadvantage. Here it is also worth noting that when egalitarians such as Isaac Puente or Rosa Luxemburg endorsed conditionality, they did so as a feature of a society that had undergone radical reconstruction in terms of its structure of opportunities and reward. They were not endorsing conditionality as such or under all circumstances, but for a specific kind of society that they aspired to create.

To recap, then, we have argued that conditionality is potentially justified by an appeal to the reciprocity principle as one element of fairness in social cooperation. However, the concern for fair terms of social cooperation also provides an important critical context for understanding and applying this principle. It suggests some important conditions which need to be met for reciprocity-based conditionality to be just. Thus, we might sum up the import of this section's argument to this point in the slogan: '(just) conditionality is conditional'.

At the level of policies and institutions, what are the sort of conditions that would have to be met in order for conditionality to be fair (according to the reciprocity-based argument we have been considering)? Based on the foregoing discussion, relevant policies/policy objectives include:

1. Due process and dignity rights. Those receiving income support must have sufficient rights within the income support system to protect them against procedural injustice and against unreasonable (undignified, harmful) demands. A particular area of concern here must be due process and dignity in assessments about the capacity to work in cases of sickness or disability.

2. Fair taxation of asset income. To prevent wealthy asset-holders violating the reciprocity principle, there must be sufficient taxation of inheritances and unearned wealth.

3. Recognition and support for care work. To ensure that care work is appropriately treated as a form of contribution in satisfaction of the reciprocity principle, there must be sufficient public recognition and material support for care work. Conditionality rules in the income support system must be calibrated to show recognition of this work. 
4. Fair equality of opportunity. For all citizens to have obligations under the reciprocity principle, there must be a sufficient degree of equality of opportunity in education, the labour market, and in access to finance (which is shaped by initial endowments of wealth).

5. Fair rewards. For all citizens to have obligations under the reciprocity principle, there must be a sufficient degree of fairness in the structure of rewards for productive efforts.

One possible objection that might be advanced at this point is that citizens are likely to disagree to some extent about what the exact principles in play here look like. For example, what constitutes a fair reward structure? Just when is asset income illegitimate because of its 'unearned' status? When are due process rights strong enough? In response, I do accept that there is indeed a range of reasonable disagreement about what the conditions involve. Even if one were to adopt a specific theoretical perspective, such as John Rawls's conception of justice, it is probable that there will be reasonable disagreement even within this perspective about necessary institutions and policies. It would surely be unreasonable for any of us to insist that conditionality is just only when the very exact conditions we have in mind are met (if, indeed, we have a very exact conception of what these conditions are). Nevertheless, there is a limit on what can count on a reasonable interpretation of any one of these conditions. I assume here that reasonable interpretations must at least be strongly informed by intuitions of the kind that underpin, for example, Rawls's theory of justice (Rawls 1999). ${ }^{6}$ These include the intuition that individuals with similar ability and motivation should have similar chances of occupational success regardless of their family background; and the intuition that market-based inequalities in reward reflective of differences in natural ability are 'arbitrary from a moral point of view' and that there is accordingly reason to question them in developing a public conception of fairness in rewards.

The striking implication of the conditions set out above, particularly if one accepts the suggested broadly 'Rawlsian' interpretation of them, is that a substantial amount of conditionality in the contemporary $U K$ (and in many other advanced capitalist countries) is 
likely to be unjust. The policies are almost certainly not in place to meet the five conditions. But conditionality in the income support system is just only if these conditions are met. Since they are not, it can't be just.

It is important to add one further thought in light of the theme of this volume. How is the context of 'austerity' likely to affect the likelihood of societies such as the UK meeting the 'conditions for conditionality'? The answer, I think, is that austerity is likely going to make it even harder to meet them. Consider, for example, that the first austerity budget of the Coalition government in the UK in 2010 included the abolition of the Child Trust Fund (CTF), a policy which aimed at ensuring every young person a modest sum of wealth on reaching adulthood. This cut almost certainly took UK society further away from meeting the fair equality of opportunity condition for fair reciprocity (White 2012). In the UK, austerity has also involved very concerted efforts to reduce spending on 'welfare' itself (Meers, Palmer, this volume). This creates pressures towards cost-cutting in the administration of the income support system which risks jeopardising the due process and dignity rights of those receiving income support.

Our discussion thus far has been quite general. To get a clearer picture of what is at stake with conditionality policy, and of the dangers that can come with unjust conditionality, let's look at one such policy in the UK that has been widely criticised. Employment Support Allowance (ESA) was introduced in the UK in 2008 (it was therefore originally designed prior to the financial crash and the arrival of austerity). It is a cash benefit intended to provide an income for those unable to get a job due to sickness or disability. A key feature of ESA is the Work Capabilities Assessment (WCA). This is supposed to test 'fitness for work'. All ESA claimants have to go through the WCA. Depending on how many points they score, based on functional impairments for which the test looks, they are then assigned to different groups. Some are denied ESA and immediately moved on to the main, means-tested 
unemployment benefit, Job Seeker's Allowance, and subject to the rigorous conditionality rules it involves. Some are granted ESA, but placed in the Work-Related Activity Group (WRAG) where they are subject to work-related activity requirements or are sanctioned. Others are placed in the Support Group, on a higher level of benefit, with no requirements to engage in work-related activity. The WCA has been the subject of widespread criticism for the alleged unfairness and inhumanity of the way it allocates sick and disabled people between these categories. ${ }^{7}$ Consequently, it has become the focus of vigorous campaigning by disabled people, with support from influential blog sites such as Sue Marsh's Diary of a Benefit Scrounger (http://diaryofabenefitscrounger.blogspot.co.uk/) and 'Bendygirl's' (Kaliya Franklin's) Benefit Scrounging Scum (http://benefitscroungingscum.blogspot.co.uk/). The problems with the WCA are also indicated by the high number of successful appeals against decisions (Gaffney 2015, 47). In 2015, the Department of Work and Pensions released figures under a Freedom of Information request which show that between December 2011 and February 2014 over 2,000 people died within two weeks of their ESA claim ending after being found 'fit for work' under the WCA (Butler 2015). In terms of the framework presented above, it is very questionable as to whether the WCA respects the due process and dignity rights of sick and disabled people. In addition, the expectation of employment itself is being pressed against the background of a labour market that is far from being justly configured for sick and disabled people in terms of fair equality of opportunity and fair rewards. Moreover, there is evidence that the effects of unjust conditionality in this case are very severe.

We should also note that there is some reason to think that austerity was a contributory factor in the rollout of the policy. Declan Gaffney points out that the policy was originally subject to an annual review for five years, including one before national rollout (Gaffney 2015, 46-47). The review in November 2010 identified problems with the WCA in 
the areas it was then being used to reassess existing benefit claimants, and recommended holding off on the national rollout of reassessment until the problems had been addressed. The government pressed ahead anyway. Why? Gaffney comments: 'The context of retrenchment cannot be ignored. In March 2011 (thus, just before the national rollout of reassessment) the DWP [Department of Work and Pensions] was forecasting that expenditure on incapacity benefits/ESA would fall from $£ 13.2$ billion to $£ 10$ billion... by $2014 / 15$, with a net saving of $£ 1$ billion...from reassessment: it is all too easy to see why a department which was already tasked with delivering major expenditure cuts would have been unwilling to sacrifice these savings' (Gaffney 2015, 47). ${ }^{8}$

\section{Responding to unfair conditionality}

So, conditionality is arguably just when it expresses a reciprocity principle. But this reciprocity-based argument must be qualified as indicated above. 'Conditionality is conditional': it is justified by reciprocity only when certain other important conditions of fairness have been satisfied. It seems likely, however, that the relevant conditions are not satisfied in many advanced capitalist countries today and that conditionality is therefore unjust in these countries at this time, given the existing policies and institutional framework. How should we respond to this apparent finding, that conditionality is just in principle but likely unjust in practice?

One response is to concede that conditionality is indeed unjust in practice but to recall that there is also a potential paternalist justification for it. Perhaps this might work, but we should note two challenges that any such proposed justification will have to meet. One is the general challenge of justifying paternalism at all. The second, and I think more serious, challenge, consists in showing that a policy that is unfair to a group of people can nevertheless be good for them. Can one make a convincing argument that coercing people receiving income support into work-related activity is good for them even if this coercion is 
unfair? I do not think unfairness rules out the possibility of (net) benefit to the receiver of income support but, as said, it presents a serious challenge to the paternalist defence of conditionality.

Putting the paternalist argument to one side, then, how might we respond? Three responses suggest themselves: (1) prioritise the conditions of just conditionality; (2) restructure the policy-making process around conditionality so as to increase the voice and influence of those who stand most to be affected; and (3) seek to reduce conditionality and move towards some form of UMI.

The first response is to prioritise at the policy level the conditions for just conditionality. If conditionality is unjust because certain policies and institutions are not in place to meet the relevant conditions for just conditionality, then let us introduce the policies and institutions we need. There is clearly something to be said for this response, particularly as an immediate response to problems with existing conditionality rules. For example, if a conditionality rule is set up and/or administered in a way that threatens the due process and dignity rights of citizens, as is arguably the case with the WCA in the UK, then reforming it to reduce or stop this is of course a sensible response (Baumberg, Warren, Garthwaite, and Bambra 2015). If the political opportunity to do it is there, one would surely wish to do it.

That said, it is worth pausing to reflect on how ambitious this response is, taken by itself, and on the risks and dangers that come with this ambition. Let's recall the five conditions for just conditionality we set out above. Now let's consider what we might have to do in policy terms to meet all of them. What would we need to do? Much more in the way of procedural rights for income support recipients? New and significant taxes to substantially reduce unearned wealth, e.g., inheritance, capital gains and land value taxes? An expansion of public subsidies to support care workers? Restructuring of the education system to foster greater equality of opportunity? Policies to address inequality in initial endowments of wealth 
and in access to finance (e.g., a restored and expanded version of the UK's CTF)? Stronger rights for sick and disabled people to accommodation in the workplace? A new legal regime to foster unionisation so as to compress wage inequalities? More progressive taxation at the top end of the income range to promote greater fairness in rewards? If the list is not endless, it is certainly going to be quite long. Considerations of social justice give us reason to pursue all of these policies, I think, but there is clearly a great deal of ambition wrapped up in setting them as political objectives.

The risk, of course, is that we are not going to achieve them. The risk is that the citizens of polities such as the UK and other advanced capitalist countries are not going to legislate for all of them, certainly not any time soon, and perhaps not ever. In the language of Rawlsian-influenced political theorists, we are at risk of having to live for some considerable time to come under 'non-ideal' conditions, where some important demands of economic fairness are not met. When we ask how we should respond to unjust conditionality our response needs to factor in this risk. It is not enough, I have come to think, to offer a list of prescriptions for public policy without considering the very substantial political risk that they will not get adopted. ${ }^{9}$

This point perhaps suggests a second line of response: to address the political system and the processes through which policy is made. In the context of this paper's topic, we might focus in particular on the policy-making process around income support and conditionality. The general idea is to prioritise reforming the process to increase the voice and influence of those who stand most to be affected by conditionality rules. A related response is to consider how to create more opportunities for legal and constitutional challenges to conditionality rules. ${ }^{10}$ Again, this response clearly has much to be said for it. Again, however, it has limitations. One limitation is that while it might work well for things like due process and 
dignity rights in the design of income support schemes, it does not directly address wider aspects of social justice on which fair reciprocity, and thus just conditionality, also depends.

The third response is to try to eschew conditionality and seek to move towards a UMI. The basic idea is that since background conditions for fair reciprocity are not satisfied, and there is a serious risk that they will not be satisfied in the future, we should proceed on the assumption that conditionality is likely to be unjust for the foreseeable future and, given the dangers from unjust conditionality, seek to move away from it as much as we can. Introducing a full UMI, set at a level sufficient to meet a standard set of basic needs, with additional benefits to cover the higher living costs of sick and disabled people, is the ideal. However, even a 'partial' UMI, set at a level below this, would arguably go some way towards reducing the stakes of unjust conditionality. ${ }^{11}$

Developing this basic idea more fully, one can present the argument for this in terms of a revisionary conception of social insurance. Conventionally, social insurance refers to welfare state schemes in which citizens pay tax-like premiums into a collective pot and in return receive benefits in the event of certain events occurring such as sickness, unemployment or old age. One other risk that we always face, however, is that our society might be in some significant way unjust in its economic structure. This risk also gives rise to dangers, particularly and more obviously so for those who are disadvantaged by the background injustice. One danger is that we become subject to unjust conditionality rules, with all the dangers that this in turn can produce in terms of weakened bargaining power, loss of dignity, and additional stress and suffering. Now imagine that we take up a variant of the Rawlsian perspective, looking at things from the perspective of the worst-off group, but here understood in the non-ideal context of an unjust society. If we take up this perspective, of those most exposed to the risk and dangers of background injustice, we would surely have reason to seek to minimise the use of conditionality. ${ }^{12}$ This way we enhance our bargaining 
power, protect our dignity and remove one possible source of stress and suffering. (One might put the argument in a form that uses Rawls's notion of the 'veil of ignorance'. If, tomorrow, we were going to be randomly allocated to a place in the economic hierarchy of our society, so that we did not know how exposed to unjust disadvantage and unjust conditionality we would be, what kind of social policy would we recommend? How much conditionality would we propose? Would we not, perhaps, seek to limit its use given the risks and dangers involved? $)^{13}$ One might thus refer to this as the social insurance argument for a UMI, acknowledging that we are using the term social insurance here in a somewhat revisionary way.

One objection to this argument for UMI as a response to unjust conditionality is that it seems to rest on simultaneously taking both pessimistic and rosily optimistic views about what is politically feasible. On the one hand, the argument is premised on the substantial risk that our society is and will remain economically unjust in significant ways. This reflects a pessimism about what is politically feasible in terms of policies to promote economic justice. On the other hand, the argument takes as its conclusion that we should seek to introduce a UMI. But obviously a full UMI this is itself a highly ambitious political objective. The conclusion therefore demands an optimism about what is politically feasible. Does this not contradict the earlier pessimism? If we are optimistic about the prospects for an UMI, why should we not also be optimistic for creating the conditions of fair reciprocity and just conditionality? And if we are optimistic about the latter, this removes the rationale for considering UMI as a response to a problem of unjust conditionality.

I think this objection is valid insofar as we think that the relative political feasibility of creating the conditions of fair reciprocity and introducing a UMI are more or less the same. However, while both are undoubtedly ambitious, this does not necessarily mean that they are equal in terms of political infeasibility. The social insurance argument has bite, so to speak, 
so long as one thinks that the introduction of a UMI is more politically feasible, and so requires less optimism, than creating the conditions for fair reciprocity. The optimism implied by the argument's conclusion does not contradict the pessimistic opening premise if the optimism involved is, so to speak, one notch or two down on the scale from the optimism required to reject this opening premise. The question then is whether we have reason to view the introduction of a UMI as more politically feasible than creating the conditions for fair reciprocity. This is a matter of political judgment, rather than philosophical argument and, moreover, the judgment involved must be very contextual in terms of time and place. My own political judgment is that in, say, the contemporary UK the introduction of at least a partial UMI, set at a level that meets a subset of basic needs, is more politically feasible than creating in full the conditions for fair reciprocity. I think one can reasonably see the argument, therefore, as supporting a direction of reform towards UMI as part of a pluralistic response to unjust conditionality.

A second objection to, or at least critical observation about, the UMI response to unjust conditionality is that it seems to allow for some injustice of its own. In the discussion above we focused on the effects of conditionality on the unjustly disadvantaged. But if we make UMI available to all this will also be enjoyed by those who are unjustly advantaged. Roughly speaking, this will include the group that Richard Arneson once referred to as 'nonneedy bohemians' - those who have highly marketable skills but would prefer to pursue more fulfilling activities than paid work (Arneson 1990). They, too, will get the UMI, and they, too, will therefore have some capacity to withdraw from work and live off the UMI. Since they are not unjustly disadvantaged by the background economic structure, we should perhaps see this behaviour as unjust. It will presumably add to the tax paid by those, advantaged or disadvantaged, who do choose to do paid work. My response to this objection is that a UMI will allow for this kind of injustice, but that at the 'non-ideal', second-best level 
of analysis we are currently working at, it is better to accept this injustice than the injustices that would occur if we make income support conditional. One might add that the division between the unjustly disadvantaged workers and 'nonneedy bohemians' in practice is not necessarily sharp: people in the latter group can easily become sick or disabled and then vulnerable to the dangers of unjust conditionality.

\section{Conclusion: a pluralist response to unfair conditionality}

In most welfare states the provision of income support is typically conditional, for most working age adults, on work-related activity. If anything, the tendency in recent years has been towards increased, tightened conditionality. The practice of conditionality finds ethical support in the principle of reciprocity: that we should all 'do our bit' in terms of making a productive contribution to society in return for the benefits we share in that others produce. However, if we accept the reciprocity-based rationale for conditionality, we also have to accept the wider concern with fairness in social cooperation of which it is one expression. We have to be consistent and equitable in applying the reciprocity principle itself, and we have to apply it in a policy and institutional context that sufficiently respects other requirements of fairness, such as in relation to the distribution of opportunity and rewards. In this sense, conditionality itself is conditional. In many societies, such as the contemporary UK, we have reason to think that the relevant conditions for just conditionality are not satisfied. How should we respond to this as citizens?

Ideally, of course, we should respond as citizens by legislating to change our policies and institutions so that the relevant conditions are satisfied. However, there is a high risk that this will not happen, certainly not in the near future. A second response, also worthy of support, is to work to improve the political, policy-making process so that the voice and influence of those who stand to be most affected by conditionality policies is increased. Third, in view of the likely limitations of the first two responses, we should also work to 
reduce conditionality itself and try to create a UMI. At the start of our discussion I made the point that a UMI is not logically entailed by the very concept of a 'social right'. However, our discussion of the justification of conditionality, and the risks and dangers of unjust conditionality, suggests that while a UMI is not logically entailed in this way, there is a strong argument in practice for including a UMI in the system of social rights. As defined here, a UMI is not identical to an unconditional basic income. But insofar as we create an unconditional basic income, this can help create at least a partial UMI. The growing interest in unconditional basic income in many countries is therefore a hopeful sign. ${ }^{14}$

\section{References:}

Albanese, Alessandra, 'The Italian Welfare State in a Time of Crisis', this volume.

Arneson, Richard, 'Is Work Special? Justice and the Distribution of Employment', American Political Science Review 84 (4), 1990, pp.1127-1147.

Bendygirl (Franklin, Kaliya), Benefit Scrounging Scum, http://benefitscroungingscum.blogspot.co.uk/

Baumberg, Ben, 'Three Ways to Defend Social Security in Britain', Journal of Poverty and Social Justice 20 (2), 2012, pp.149-161.

Baumberg, Ben, Warren, Jon, Garthwaite, Kayleigh, and Bambra, Clare, Rethinking the Work Capability Assessment (London, Demos, 2015).

Butler, Patrick, 'Thousands have died after being found fit for work', The Guardian, 27 August 2015, http://www.theguardian.com/society/2015/aug/27/thousands-died-after-fit-forwork-assessment-dwp-figures

Cochrane, Clare with Haddad, Moussa, Fooks, Louie, and Garton, Jane, Something for Nothing: Challenging negative attitudes to people living in poverty (Oxford, Oxfam, 2010), http://policy-practice.oxfam.org.uk/publications/something-for-nothing-changing-negativeattitudes-to-people-living-in-poverty-114046

Duncan, Andrew, 'Welfare Conditionality, Inequality and Unemployed People with Alternative Values', Social Policy and Society 9 (4), 2010, pp.461-473.

Gaffney, Declan, 'Retrenchment, Reform, Continuity: Welfare Under the Coalition', National Institute Economic Review 231, February 2015, pp.44-53.

Hobhouse, Leonard T., The Labour Movement (New York, Macmillan, 1912).

King, Jeff, 'Social Rights and Welfare Reform in Times of Economic Crisis', this volume. 
Lembke, Ulrike, 'Welfare Reforms in Germany: Between Activation Policies, Social Cutbacks, Legislative Discretion and the Fundamental Right to Minimum Subsistence', this volume.

Marsh, Sue, Diary of a Benefit Scrounger, http://diaryofabenefitscrounger.blogspot.co.uk/

Marshall, T.H., 'Citizenship and Social Class', in T.H. Marshall, Citizenship and Social Class (Cambridge, Cambridge University Press, 1950).

Mead, Lawrence, The New Politics of Poverty: The Nonworking Poor in America (New York, Basic Books, 1992).

Meers, Jed, 'Shifting the Place of Social Security: Welfare Reform, Austerity and Social Rights in the UK', this volume.

Miller, David, Principles of Social Justice (Cambridge, MA, Harvard University Press, 2000).

Otsuka, Michael, Libertarianism without Inequality (Oxford, Oxford University Press, 2003).

Painter, Anthony, and Thoung, Chris, Creative citizen, creative state: the principled and pragmatic case for a Universal Basic Income (London, RSA, 2015).

Palmer, Ellie, 'Holding Government to Account in a Recessionary Climate: The Values of Public Law', this volume.

Puente, Isaac, Libertarian Communism (1932), http://libcom.org/files/Libertarian\%20communism\%20-\%20Isaac\%20Puente.pdf

Rawls, John, A Theory of Justice: Revised Edition (Cambridge: MA, Harvard University Press, 1999 [1971]).

Roman, Diane, 'The Impact of the Financial-Economic Crisis on the Guarantee of Social Welfare Rights: The Case of France', this volume.

Shelby, Tommie, 'Justice, Deviance, and the Dark Ghetto', Philosophy and Public Affairs 35 (2), 2007, pp.126-160.

Utrilla, Dolores, 'Economic Crisis and Welfare Reforms in Spain', this volume.

White, Stuart, 'Social Rights and the Social Contract: Political Theory and the New Welfare Politics', British Journal of Political Science 30 (2), 2000, pp.507-532.

------, The Civic Minimum: On the Rights and Obligations of Economic Citizenship (Oxford: Oxford University Press, 2003).

------, 'A Social Democratic Framework for Benefit Conditionality', in Kate Stanley and Liane Lodhe with Stuart White, Sanctions and Sweeteners: Rights and Responsibilities in the Benefits System (London, Institute for Public Policy Research, 2004).

------, 'Basic Capital: A Policy Whose Time Has Come... and Gone?', The Good Society 21 (1), 2012, pp.61-73. 
Notes: ${ }^{1}$ This is certainly the case in the UK. Intensification of conditionality under the Labour
governments of $1997-2010$ is noted by Baumberg 2012 . Further tightening under the
Coalition government of $2010-15$ is noted by Gaffney 2015 . Albanese, Lembke, and Roman,
this volume, note moves towards greater conditionality in, respectively, Italy, Germany, and
France.

${ }^{2}$ See also Duncan 2010, 465-466, who reports in his interview study strong majority acceptance of the 'wealth ethic', according to which it is legitimate not to work provided one has independent wealth and so no need to claim state transfers.

${ }^{3}$ I owe this phrase to Declan Gaffney.

${ }^{4}$ This might be harder than it sounds if there is also an effort to 'personalise' packages of support and obligation for benefit recipients. 'Personalisation' might be desirable in some ways but might also increase the challenge of ensuring consistency and equity of treatment.

${ }^{5}$ The early twentieth-century British 'New Liberal', Leonard Hobhouse, puts the point well: 'The moralist...is concerned lest we should insist too much on rights and too little on duties.... The only doubt is whether the stern disciplinarians who insist on self-support fully realise the revolutionary nature of their doctrine. If a system is wrong which maintains an idle man in bare necessaries, a system is much more wrong which maintains an idle man in great superfluity, and any system which allows the inheritance of wealth on the great scale is open to criticism on this score' (Hobhouse 1912, pp.16-17).

${ }^{6}$ This said, I think a number of non-Rawlsian perspectives would also support an approach like that suggested here, and the judgment that contemporary advanced capitalist societies do not meet the conditions of fair reciprocity. Such non-Rawlsian approaches arguably include the pluralistic theory of social justice put forward by David Miller and some versions of leftlibertarianism such as that proposed by Michael Otsuka (Miller 2000, Ostuka 2003).

${ }^{7} \mathrm{~A}$ key problem is that the WCA is a test of functional impairment but it is a mistake to make any direct or general inferences about a person's real-world capacity to do a job simply from a particular level and pattern of functional impairment. See Baumberg, Warren, Garthwaite, and Bambra 2015 and Palmer, this volume.

${ }^{8}$ Gaffney adds: 'In the event, expenditure in $2014 / 15$ is now forecast to be $£ 3.7$ billion higher than forecast in 2011.'

${ }^{9}$ This represents a change from the perspective I set out in White 2003.

${ }^{10}$ In the UK, this would ultimately require the creation of a written constitution, something of a constitutional revolution. Meers, this volume, and Palmer, this volume, discuss the resources in the UK for challenging the legality of reforms to the benefits system. However, as Utrilla, this volume, notes in her discussion of welfare reforms in Spain, even with a written constitution that includes social rights, courts tend to give legislatures some room for discretion. Albanese's discussion of the Italian case in this volume points out that Italian courts have recently retreated somewhat from judicial activism in support of individual social 
rights. For a discussion of what we ought to expect from courts in the context of austerity, see King, this volume.

${ }^{11}$ In the UK, many key cash benefits, such as Job Seeker's Allowance, are set below a defensible basic needs standard. What I have in mind by a 'partial' UMI, therefore, would be something like Job Seeker's Allowance minus the conditionality rules that are presently attached to it.

${ }^{12}$ A qualification to this would be for any paternalist arguments that can pass the challenge I discussed earlier in this article.

${ }^{13}$ I do not want to put too much emphasis on arguing from a 'veil of ignorance'. By itself, this kind of thought-experiment is too dependent on assumptions about attitudes to risk on the part of those behind the veil. The important thing is to think about how conditionality looks from the standpoint of the worst-off and the thought-experiment may have some use in helping us access this perspective.

${ }^{14}$ See, for example, Painter and Thoung 2015. 